Comparative Philosophy Volume 8, No. 1 (2017): 114-128

Open Access / ISSN 2151-6014

www.comparativephilosophy.org

CONSTRUCTIVE ENGAGEMENT DIALOGUE

\title{
THE PERSPECTIVE AND PERSPECTIVE-TRANSCENDING DIMENSIONS OF CONSCIOUSNESS AND ITS DOUBLE-ABOUTNESS CHARACTER: BRIDGING SEARLE AND ZHUANG ZI
}

BO MOU

\begin{abstract}
What I intend to do here are closely related three things. First, in response to Searle's "reply" comments on my previous article "Searle, Zhuang Zi, and Transcendental Perspectivism", I will clarify and further elaborate one of the central points concerning the "perspective" dimension and "perspective-transcending" dimension of consciousness there. Second, more substantially, I will strengthen my point by explaining the "double-aboutness" character of consciousness which is intrinsically related to the foregoing two dimensions of consciousness concerning its "hooking-up-to-objects" capacity; through a semantic-ascent strategy, I will also explain how the point has substantial theoretic implications for exploring the issue of how the cross-perspective engagement is possible. Third, I will explain how bridging Searle's and Zhuang Zi's resources in view of the double-aboutness character of consciousness can contribute to our understanding and treatment of the foregoing issue.
\end{abstract}

Keywords: cross-perspective engagement, double aboutness, double reference, perspective dimension of consciousness, perspective-transcending dimension of consciousness, Searle, Zhuang Zi

In this "further engagement" article in response to Searle's valuable and thoughtstimulating "Reply" writing ("Searle's "Reply", for short below) to my contributing essay "Searle, Zhuang Zi, and Transcendental Perspectivism" to the volume "Searle's Philosophy and Chinese Philosophy" ('my JS-CP article' for short below), I will do three closely related things. First, I will clarify and further elaborate one of the central points in my JS-CP article concerning the "perspective" dimension and "perspectivetranscending" dimension of consciousness, part of whose expressions might lead Searle to identify some part of my view in an unexpected way in his "reply" comments. Second, more substantially, I will strengthen my point by explaining the "double-aboutness" character of consciousness which is intrinsically related to the

MOU, BO: Professor of Philosophy, San Jose State University, California, USA. Email: bo.mou@sjsu.edu 
foregoing two dimensions of consciousness concerning its "hooking-up-to-objects" capacity; through a semantic-ascent strategy in explaining the double-aboutnesss character of consciousness, I will also explain how the point has substantial theoretic implication for exploring the issue of how the cross-perspective engagement is possible. Third, I thus further explain how bridging Searle's and Zhuang Zi's resources in view of the double-aboutness character of consciousness can contribute to our understanding and treatment of the foregoing issue.

1.

For the sake of the reader's understanding of due background, let me first briefly introduce what is at issue between Searle and me in this engaging discussion (concerning one of the major points in my JS-CP article and one of the major contents in Searle's "Reply"), what we jointly agree to and what we seem to disagree to. As explained in my JS-CP article, Searle and Zhuang Zi both maintain a kind of objective perspectivism in their distinct ways. It is known that the word 'perspectivism' per se is a blanket term used to (ambiguously) refer to a number of different kinds of meta-philosophical attitudes, methodological guiding principles, or even more systematic methodological frameworks concerning how to look at the nature and status of a variety of perspectives taken to approach an object of study. There are two types of perspectivism, subjective perspectivism and objective perspectivism. The former is sometimes used as another label for, or characterized in terms of, a radical "anything goes" version of conceptual relativism; subjective perspectivism is actually taken as one major argument against external realism and for idealism/antirealism. In contrast, objective perspectivism bases the relevance and eligibility of a perspective (given an object of study) on whether the perspective points to some aspect that is really or objectively possessed by the object of study. When examining features of consciousness and intentionality, Searle identifies and emphasizes one intrinsic feature of intentionality, i.e., aspectuality. He asserts that all intentionality is aspectual: consciousness of some object is always consciousness of it as such and such from a certain perspective or from a point of view. In this way, “...[a]11 representations represent their objects, or other conditions of satisfaction, under aspects. Every intentionality state has what I call aspectual shape" (Searle 1992, 131). He thus calls this feature of consciousness 'the perspectival character' or the 'aspectuality' of intentionality. Searle's version of perspectivism (his own label is 'perspectivalism'; op.cit) in analyzing consciousness, together with his account of external realism, implies (or at least is compatible with) two general positions concerning how to look at seemingly competing points of view. One is a kind of conceptual relativism, which Searle explicitly addresses and endorses, to the effect that "[a]11 representations of reality are made relative to some more or less arbitrarily selected set of concepts" (Searle 1995, 161). Such a modest version of conceptual relativism, as Searle emphasizes it, does not entail the negation of, but rather presupposes, external realism, which maintains that reality exists independently of our representations of it. The other general position, implied by his doctrine of 
perspectivalism in analyzing consciousness and intentionality together with his account of external realism and his doctrine of social reality, in my view, is essentially a kind of objective perspectivism.

However, to my knowledge, Searle has not explicitly addressed it, and some significant components of a complete account of objective perspectivism have yet to be further explored. On the one hand, Searle's various accounts strongly suggest a kind of objective perspectivism to the extent that, given an objective object of study in the sense of 'objective' as specified by Searle, one looks at the object from a perspective of a certain conceptual scheme. On the other hand, a complete account of objective perspectivism needs to go further: it is consistent with or even includes, but does not simply amount to, the foregoing modest version of conceptual relativism plus external realism. First, as far as their respective focuses are concerned, the latter emphasizes that, given (the same one aspect of) an objective object of study, one always makes one's (intentional) judgment or representation of it from some perspective associated with a certain conceptual system; in contrast, the former stresses that, given an object of study and thus the identity of a variety of genuine aspects of the object (and given a certain conceptual scheme or system), there are a variety of eligible perspectives that point respectively to various aspects of the object, and thus there is the need for an account of how to look at the relation between eligible perspectives. Second, what makes the foregoing issue reasonable and adequate, I contend, lies in the following fact concerning consciousness: besides its aspectual character, consciousness also simultaneously has its aspectualitytranscending character, i.e., in my terms, the perspective-transcending dimension of consciousness.

My view in my JS-CP article is this: a complete account of objective perspectivism is thus expected to give adequacy conditions for understanding the due relation between various eligible perspectives concerning an object of study; this per se requires the agent to be able to "transcend" a certain finite perspective under aspectuality for the sake of (having capacity of) pointing to the object as a whole and seeing the limit of the finite (eligible) perspective and the connection among various finite (eligible) perspectives. In this way, a due account of the aspectualitytranscending feature of consciousness would contribute to our understanding of how the cross-perspective engagement is possible.

At this point, Searle seems to disagree with me. In his "Reply", Searle presents my foregoing point this way: "it seems to me that he [Mou] sometimes talks as if 'transcendental perspectivalism' would enable consciousness to rise above all perspectives and thus dispense with aspectual shape" (Searle 2008, 431). I think that Searle's evaluative comments here are partially correct and, I am afraid, partially miss one substantial part of my point. It is correct to the extent that I do think that one, any human being, has the capacity to enable consciousness to "rise above all [finite, local] perspectives"; however, it is not my view that "[one] thus [has consciousness] dispense with aspectual shape". My view does not imply that one can stay in a "nowhere" position (while going beyond all finite perspectives) but this: one can have consciousness to simultaneously (cf., Mou 2008, 408) do both: taking a certain finite 
perspective while being able to see the limit of one's currently taken finite perspective and its connection with some other finite perspective(s) at the same time; the latter consciousness activity requires the "perspective-transcending" capacity of consciousness. Indeed, It is not something odd or mysterious: imagine that one looks at the Sather Tower Building in front of Searle's Department building - such a look is always from a certain aspectual point of view, as Searle has correctly emphasized; however one can have one's capacity of simultaneously going beyond that specific finite perspective to realize its "limit" (i.e., only the aspect of the Building covered by one's current "working" aspectual point of view, instead of the others, is actually seen by one's eye-sight sense) and its connection with some other eligible perspectives that points to some other aspects of the Tower.] Searle continues on the same page: "I wish to distinguish on the one hand between $<1>$ the claim that we should always be able to rise above our local cultural prejudices and points of view, and on the other hand $<2>$ the claim that we might have representations which had no point of view and no aspect under which the conditions of satisfaction are represented" (Searle 2008, 431; the number labels are mine). What is addressed in my JS-CP article share the same sentiment as Searle's $<1>$ in the foregoing citation, that is, "we should always be able to rise above our local cultural prejudices and points of view"; however, the view $<2>$ (i.e., "we might have representations which had no point of view and no aspect under which the conditions of satisfaction are represented") is clearly not mine.

As I see it, what I label 'aspectuality-transcending' capacity in the JS-CP article or 'perspective-transcending' capacity here is largely the same as what Searle labels 'imagination' capacity in the subsequent paragraphs in his "Reply", where Searle addresses the important role played by the capacity of the imagination in this way: "...[p]art of being able to perceive something is being able to imagine what it would look like from the other side and having a perception of something is awareness that it has another side. It need not be conscious, but you have to have the capacity to imagine its other side. It is a Background ability that if you are able to look at a tree you have to have the capacity to know that there is another side to the tree and that you could walk around the tree to see the other side....this capacity of the imagination is absolutely crucial to understanding moral, social and political behavior" (Searle 2008, 434). Then I am not sure to what extent Searle captures my point in this connection; for, when addressing "imagination", he seems to use such psychologically-oriented folk terms as 'imagination' to address essentially the same point as that of what I intend to deliver by using the term 'aspectuality-transcending' (a more or less quasi-theoretic term). However, in view of the principle of charity in interpretation, I would not say that Searle would thus become inconsistent with himself in this connection; rather, I would attribute this to my terminology use which might lead Searle to identify my view in an unexpected way: the phrase I used in the JS-CP article, 'aspectuality-transcending', includes Searle's own term 'aspectuality' which goes with his own specification; when I borrow this term as part of the foregoing phrase, it might lead Searle to think that the addressed "aspectualitytranscending" dimension of consciousness means that "we might have representations 
which had no point of view and no aspect under which the conditions of satisfaction are represented". That is one consideration for my changing the phrase 'aspectualitytranscending' in my JS-CP article to the current terminology 'perspectivetranscending' here to deliver what is intended to capture in my account.

As Searle addresses the capacity for imagination which is part of what I intended to deliver in the JS-CP article, on the one hand, I find that our positions actually are more close in one connection: if I use Searle's terms, part of the same point can be delivered in terms of the "aspectual" dimension and the "imagination" dimension of consciousness. However, on the other hand, I also note that there is some substantial difference. Let me explain this by looking at the difference in Searle's terminology and mine. In my view, the term 'imagination' does not adequately capture the "perspective-transcending" dimension of consciousness; the considerations for which I would not use the term 'imagination' are substantial, instead of merely verbal. First, the term 'imagination' seems too narrow to cover the wide spectrum of the "perspective-transcending" dimension of consciousness, especially its wisdomcultivation-oriented part which does not result from mere imagination. Second, the term 'imagination' seems too wide to exclude some sorts of wild imagination which would not be rendered adequate by the minimal normative character of the "perspective-transcending" dimension of consciousness that is to reject the "anythinggoes" expectation. Third, more substantially, the more or less psychologically oriented concept of imagination (or the capacity for imagination), as I will explain in the next section, cannot adequately capture one significant dimension of the doubleaboutness character of consciousness which plays a certain crucial role in the interplay of the "perspective" and "perspective-transcending" dimensions of consciousness. The third consideration is related to the subject in Section 2 of this "further engagement" writing.

2.

Indeed, this writing is not just for the sake of the foregoing clarification, what would have this "further engagement" writing more substantial is this: I intend to strengthen my point on the "perspective" and the "perspective-transcending" dimensions of consciousness as made in the JS-CP article by addressing and explaining the "doubleaboutness" character of consciousness concerning how to hook up objects of thought for the sake of addressing and exploring the significant issue of how the crossperspective engagement is possible.

What is addressed and emphasized in my JS-CP article in terms of the "perspective" dimension and the "perspective-transcending" dimension of consciousness actually points to one fundamental character of consciousness concerning how it is possible for consciousness to hook up to an object that is thought about in consciousness, which might as well be labeled '(synchronic) doubleaboutness' character of consciousness: given an object as a whole with its multiple specific aspects, the "perspective" dimension of consciousness is about some specific aspect(s) of an object thought about in consciousness, while the "perspective- 
transcending" dimension of consciousness is synchronically about the object as a whole, instead of being restricted to one specific aspect of the object. The former, the "object-specific-aspect aboutness" dimension of the double-aboutness character of consciousness constitutes the base part of the "perspective" dimension of consciousness in this sense: it points to the targeted specific aspect of the object as the "metaphysical" base on which any eligible "perspective" elaborations in consciousness as further comments on that specific aspect of the object can be built and evaluated in an "objective" way (understood in a broad sense, in contrast to "anything goes"). On the other hand, the latter, the "object-whole aboutness" dimension of the double-aboutness character of consciousness constitutes the base part of the "perspective-transcending" dimension of consciousness in the following sense: it points to the object as a whole which constitutes the "metaphysical" unifying base on which distinct eligible perspectives that point to different specific aspects of the object can be complementary and make joint contribution to a complete understanding of the identity and nature of the object; it is the starting-point base on which any further perspective-transcending thoughts, insights or wisdom-oriented visions can be further developed or cultivated in adequate ways. It is noted that, different from those parts in the wisdom-cultivation-oriented "high end" of a wide spectrum of the coverage of the "perspective-transcending" dimension of consciousness, the "object-whole-aboutness" part, so to speak, occupies the "low end" of the wide spectrum of the "perspective-transcending" dimension of consciousness; it is more or less inter-subjective to this extent: at the level of consciousness activities in thinking about objects, at least for many objects of thought in people's adult lives, perhaps every normal human agent has her first-hand consciousness experience of making her conscious perspective shift from one specific perspective to another specific perspective about the same object as a whole (sensitive to her distinct current focuses on distinct aspects of the object), while at the same time transcendentally realizing that all these distinct perspectives are about the same object as a whole, as I will illustrate it through a semantic-ascent way below; at the metaconsciousness level, perhaps every normal human agent (can) understand and realize that we can all think and/or talk about the same object even though we may say different things about it, whether or not the agent herself currently realizes (or psychologically/cognitively imagines) the contents of these different things (i.e., different perspectives that point to distinct aspects of the object).

With the foregoing general, but quite abstract, characterization of the doubleaboutness of consciousness, the point can be effectively delivered in a semanticascent way. That is, the double-aboutness of consciousness can be explained through a semantic-ascent strategy by explaining its semantic-ascent counterpart, the doublereference character of our basic language employment of saying something of an object, given that reference as the semantic relation is essentially an "aboutness" relation between language expressions as referring names and objects as referents. ${ }^{1}$

\footnotetext{
${ }^{1}$ The term 'reference' or 'referring', just like 'talk about' or 'talking about', is used here as a lessmetaphysically-loaded neutral term expressing the "aboutness" semantic relation between a word, or
} 
This strategy is not merely a technical means by which the double-aboutness can be effectively expressed and illustrated; it is more substantial. (1) Language as an (or even "the") effective textual means keeps and preserves already-generated results and imprints of consciousness for the sake of communication, further reflection and evaluation (by the consciousness agent herself and others). (2) In some substantial cases, language uses, as indispensable medium, help consciousness agents create and generate sophisticated thoughts. (3) More relevant here is the direct-reference function of referring names which enables a consciousness agent as a speaker to directly think about (via talking about, i.e., referring to) an object as a whole (without necessarily relying on psychological and cognitive imagination, at least in case of pointing to it via a proper name) through a communication link. ${ }^{2}$ These distinct but related types of human language employment do matter, both for the sake of understanding of the "double-aboutness" character of consciousness and for the sake of our understanding and treatment of the issue of how the cross-perspective engagement is possible through exploring its consciousness foundation via its "double-aboutness" character. First, when examining different approaches from different traditions, what we typically face and handle are texts under examination, instead of their authors, especially when we carry out cross-tradition dialogue with ancient thinkers via their texts. Second, one substantial task of comparative philosophy or doing philosophy comparatively is to forge further philosophical ideas from constructively engaging examination of different approaches; the thinking process of creating sophisticated philosophical ideas cannot be processed systematically, clearly, effectively and consistently without language uses as medium. Third, the same object whole that are thought about in distinct tokens of consciousness is identified, maintained and secured through the-same-object-related communication links of its (possibly different) referring terms (in the same or different natural languages) in talking about the object whole. In these senses, and to this extents, the double aboutness at the level of consciousness and the double reference at the level of language employment are intrinsically related and closely connected in a parallel way.

It is known that one basic language employment is this: when referring to an object (a physical object in space and time, a number in math, or a fictional figure in a story) via a referring name in linguistic activities (such as communication, doing math via math language, etc.), typically and generally speaking, a speaker intends to say something (and she can say different things or different speakers can say different things) of the (same) object as a referent, or, in a more semantically-oriented way (treating those pragmatic elements like "a speaker's intention" as the presupposed background elements), some thing is said of a referent. In the following, first, I illustrate the double-reference character of the foregoing basic language employment

collection of words, and some objects, whether it "actually exists", instead of being restricted to hold only between a word and some thing that actually exists (cf., Crane 2013, 9-10).

${ }^{2}$ This point has been widely recognized now; for its systematic and powerful explanation, see Kripke 1980 , although one does not necessarily accept the metaphysical commitment involved in his "causalhistorical" account of referring. 
via two typical groups of sentences in our ordinary linguistic practice, each of which says something about what a referring name refers to, respectively concerning two typical kinds of referring names (proper names such as '(Jerry) Brown' that refers to an individual object, and descriptive referring names such as 'the white horse' that refers to either (a typical case) one collection of individual objects that fit the description or one distinctive (or even unique) individual object that fits the description $^{3}$ ). Second, I highlight a number of pre-theoretic characterizations of our ordinary "double-reference" linguistic practice. ${ }^{4}$

Let me start with the first sample group of sentences, giving a preliminary "double-aboutness" analysis in terms of "double-reference" semantic paraphrase to each of them:

\section{(1.1) Brown was born in San Francisco on $7^{\text {th }}$ April 1938.}

A preliminary "double-aboutness" analysis in terms of "double-reference" semantic paraphrase: in this sentential context, 'Brown' refers to Brown as a whole and at the same time points to his specific "birth" part (talking about his "birth" part as well as Brown as a whole person); the sentential predicate "further comments" on Brown as a whole in view of this specific-part referent. ${ }^{5}$

(1.2) Brown had a headache (head-ache) on $20^{\text {th }}$ January 2017.

A preliminary "double-aboutness" analysis in terms of "double-reference" semantic paraphrase: given that it is true, in this sentential context, 'Brown' refers to Brown as a whole and at the same time points to his specific "head" part (talking about his "head" part as well as Brown as a whole person); the sentential predicate "further comments" on Brown as a whole in view of this specific-part referent.

\section{(1.3) Brown is now the Governor of California.}

A preliminary "double-aboutness" analysis in terms of "double-reference" semantic paraphrase: in this sentential context, 'Brown' refers to Brown as a whole and at the same time points to his current specific "governorship" part

\footnotetext{
${ }^{3}$ In the latter case, a descriptive name is sometimes labeled 'a definite description' in its technical sense.

${ }^{4}$ It is noted that all the following linguistic observations that are given in "pragmatic" terms can be presented in non-pragmatic terms when the focus is on the semantic dimension of the addressed linguistic phenomenon.

5 A separate writing by this author presents a double-reference-related "subject-perspective" account of predication which gives a detailed explanation of how the semantic-whole referent in view of the specific-part referent (in "perspective" focus) is "further commented" on via the sentential predicate. With consideration of the major purpose here, I will not elaborate the predication part of such preliminary "double-aboutness" analyses in this writing. Nevertheless, a brief explanation of it will be given in the third pre-theoretic characterization of the "double-aboutness" character below in terms of the "double-reference" analysis below. Also see footnote 8 below.
} 
(talking specifically about his current "governorship" part as well as Brown as a whole person); the sentential predicate "further comments" on Brown as a whole in view of this specific-part referent.

(1.4) Brown today is not the same as Brown yesterday.

A preliminary "double-aboutness" analysis in terms of "double-reference" semantic paraphrase: in this sentential context, 'Brown' refers to Brown as a whole and at the same time points to his current specific "today" part (talking specifically about Brown's current "today" part as well as Brown as a whole person); the sentential predicate "further comments" on Brown as a whole in view of this specific-part referent.

In so saying, we are not using the same name to refer to four different persons but the same one person, Jerry Brown. So we can simply say:

(1) Brown was born in San Francisco in 1938, had a headache on $20^{\text {th }}$ January 2017, is now the Governor of California and is not the same as Brown yesterday.

The second sample group of sentences, which go with descriptive referring names as their subject names are given as follows:

(2.1) The white horse (the collection of white horses) is (the identical to) the horse (the collection of horses or the horse collection) [regarding some attribute that they share].

A preliminary "double-aboutness" analysis in terms of "double-reference" semantic paraphrase: in this sentential context, 'the white horse' refers to the collection of white horses as a whole and at the same time points to the specific "horseness" attribute (talking specifically about the common or jointly shared "horseness" attribute as well as the whole collection of white horses); the sentential predicate "further comments" on the collection of white horses as a whole in view of this specific part.

(2.2) The white horse (the collection of white horses) is not (the identical to) the horse (the collection of horses or the horse collection) [regarding some distinct attribute which is possessed by any white horse but not by all horses].

A preliminary "double-aboutness" analysis in terms of "double-reference" semantic paraphrase: in this sentential context, 'the white horse' refers to the collection of white horses as a whole and at the same time points to the specific part, the distinct attribute of possessing white color, which is possessed by any white horse by not by any member of the horse collection; the sentential predicate 
"further comments" on the collection of white horses as a whole in view of this specific part.

In so saying, we are not using the same name to refer to two different collections of things but the same one collection, that of white horses. So we can simply say:

(2) The white horse is identical to the horse regarding some shared attribute, and is not identical to the horse regarding some distinct attribute that is possessed by the white horse but not all horses.

Now I address and highlight several pre-theoretic characterizations of the "doubleaboutness" character of consciousness in "semantic-ascent" terms of the "double reference" character of the basic language employment (i.e., saying something about an object) as illustrated by the above two paradigm cases.

(1) In our linguistic practice, we use '(Jerry) Brown' to refer to Jerry Brown as a whole with his various attributes and in his various relations (to some other objects) ${ }^{6}$ such that we can talk about him while pointing respectively to certain attributes (in perspective focuses) and make various "further comments" on him. In this way, the name 'Brown' designates the same object (in our actual world), Jerry Brown, who himself is an object as a whole that unifies the collection of its various (diachronic and synchronic) specific (attribute) parts. No matter which specific part of Brown is focused on in a given sentential context (as one specific-part referent), the same object, Brown with all his rich attributes, as the semantic-whole referent is talked about or thought about.

(2) In each of these declarative sentences or statements, when the object as a whole that is said of is referred to or designated (say, Brown as a whole person), a certain specific part is also at the same time referred or points to ${ }^{7}$ whose identity is to sensitive to the focus as shown or revealed in the given sentential context, which is taken to be possessed by Brown, and which is up to some further comment via linguistic predicate expression in the sentence. In other words, there are two levels of what is about here: first, about Brown as a whole; second, about some specific part in perspective focus. Given that, in the aforementioned basic language employment fact of something being said of an object, what is referred to is essentially what a sentential context is about, the basic language employment fact has thus its fundamental "double-reference" character.

(3) The specific-part referent has its dual status: on the one hand, as explained above, it is part of what is said about in the sentential context and thus it has its "reference" status; on the other hand, in the given sentential context, it points to in focus and thus specifies a certain specific part of the designated referent whole as part

\footnotetext{
${ }^{6}$ Note that it is presupposed, instead of being further explained, that 'Brown' here designates Jerry Brown via various relevant "pragmatic" contributing elements to the communication link between the use of the name and Jerry Brown as the current Governor of California.

${ }^{7}$ Or more than one specific attribute part. For the sake of simplicity of discussion, I focus on the onepart case.
} 
of what is said about the semantic-whole referent, although, generally speaking, the sentential predicate "further comments" 8 on the object as a whole in view of this specific-part referent that is referentially and logically prior to what the sentential predicate literally expresses. In this sense, and to this extent, the predication in the basic language employment right starts at the specific-part reference, although, generally speaking, the latter (or the predicative content of the subject referring name via its specific-part reference) does not exhaust the former in the sense that the predication in the basic language employment (in most cases) does not stops at what the (explicit or implicit) descriptive or predicative content of the subject referring name in the sentential context gives but is further completed and complemented by what the sentential predicate expresses (via its "further comment" on the designated object as a whole in view of the specific-part referent).

(4) The speaker can change her focus from one aspect of an object, which the subject expression designates, to another aspect which she already knows (whether or not she then would fully know the object about all its aspects); she can make, say, the statements (1.1)-(1.4) on different occasions for distinct purposes and with distinct perspective focuses. What makes such a focus shift possible lies in this, though it seems trivial: the speaker presupposes and believes that the same object possesses those specific-part aspects, whether or not she purposely focuses on a certain aspect, among others, in her current statement. ${ }^{9}$

(5) A person can successfully designate an object as a whole via a communication link, with her understanding that it is an object with multiple attributes, while without actually knowing (or psychologically imagining) exactly how many, and what, its attributes are). It is so due to some epistemological reason (various epistemic restrictions) and/or due to some metaphysical reason (given that many of the objects around us keep changing and developing).

One note is due. One might doubt this way: if the specific-part referent counts as something that is about (that is, if the "object-specific-aspect aboutness" dimension of the "double-aboutness" character of consciousness counts as a type of "aboutness"), it is a kind of "about about": it itself is about the semantic-whole referent, and it belongs to what is said about the semantic-whole referent, and it includes "predicative" element and thus it is not something really referential. My reply is this. Given that what is referred to is essentially what a sentential context is about, indeed there are two levels of what is about involved in the basic language employment fact: first, about the designated semantic-whole referent; second, about some specific part in focus; the basic language employment fact thus has its fundamental "double reference" character. To this extent, the specific-part referent is really referential in

\footnotetext{
${ }^{8}$ Perhaps the word 'comment' would bring about a "theoretically-loaded" impression; the term used here is intended to be "user-friendly" in capturing what really happen in the addressed basic language employment; surely it can be replaced by another "user-friendly" word which a reader would prefer.

${ }^{9}$ This linguistic observation shows that we actually render the object richer (or "thicker" in metaphoric terms) than what the above second linguistic observation (explicitly addressing only one aspect or certain finite aspects in focus) shows us and further strengthens the point of the first linguistic observation.
} 
nature. Moreover, even when a proper name serves as the subject referring name and the identity of the specific-part referent is linguistically expressed through the sentential predicate, the specific-part referent is referentially and logically prior to the sentential predicate, as illustrated by those sample sentences (1.1) through (1.4).

In the above, I endeavor to explain how the interplay and joint contribution of the "perspective" and "perspective-transcending" dimensions of consciousness via its "double-aboutness" character is possible through the foregoing semantic-ascent strategy of exploring the "double-reference" character of the basic language employment. In so doing, I actually present another substantial consideration for taking this semantic-ascent strategy to capture the point of the "double-aboutness" character of consciousness in view of its "perspective" and "perspectivetranscending" dimension: the "object-whole-reference" dimension of the doublereference character of people's consciousness-related linguistic capacity and linguistic practice is not necessarily related to the psychologically-oriented imagination, which Searle addresses in his "Reply", but naturally embedded in people's referring practice via a communication link between a referring name used to refer to an object and the object as a semantic-whole referent; ${ }^{10}$ it is "perspectivetranscending" in nature to the extent that it has the speaker naturally see distinct aspects of the semantic-whole referent and thus see the none-holistic nature of one specific-part referent and the connection of various specific-part referents together with their associated "further-comment" sentential predications in distinct perspective focuses. This would help us capture the genuine point of the relation between the "perspective" and "perspective-transcending" dimensions of consciousness through its "double-aboutness" character. Given that the double-aboutness character of consciousness is implemented through the double-reference character of our language employment to the aforementioned extent, this is one connection in which Searle's more or less psychologically oriented concept of imagination (or the capacity for imagination), as mentioned at the end of the previous section, cannot adequately capture the "object-whole-aboutness" part of the double-aboutness character of consciousness (as the inter-subjective base part of the "perspective-transcending" dimension of consciousness) as well as those parts in the wisdom-cultivation-oriented "high end" of the spectrum of the "perspective-transcending" dimension of consciousness, for both cannot be achieved and secured through imagination alone (the former might be even not related to "imagination" in some cases, as explained before).

In my view, the double-aboutness character of consciousness provides the consciousness foundation for exploring the issue of how the cross-perspective engagement is possible, while the double-reference character of the basic language employment provides its semantic foundation; they are essentially the same in this regard as shown in the foregoing "semantic-ascent" explanation of their relation. As

\footnotetext{
${ }^{10}$ An earlier systematic and influential account of such a communication link is developed by Kripke usually labeled "causal-historical account of reference" (Kripke 1980). For the sake of the purpose here, the involved debate between the Kripkean line and the Fregean line on the issue of reference will not addressed in this writing.
} 
explained in this section, while people take distinct perspective approaches ${ }^{11}$ to an object of study thus being about distinct aspects of the object in consciousness through language engagement, the "perspective-transcending" dimensions of their respective tokens of consciousness enables them to have the "same-object-whole" common ground for their cross-perspective engagement.

3.

Before I explain how the double-aboutness character of consciousness can provide the effective common ground for constructively bridging Searle and Zhuang Zi via their complementary resources, in view of these relevant resources in Searle's account as addressed in the previous two sections, let me reiterate one key passage from Zhuang Zi's text [in Chapter 2, Qi-Wu-Lun ( 齊物論 On The Equality of Things), of the Zhuang-Zi] which highlights the two crucial points of Zhuang Zi's transcendental perspectivism as explained in my JS-CP article:

Everything has its that aspect and its this aspect. One cannot see the this aspect of a thing if one looks at the thing from the perspective of the that aspect; one can see the this aspect if one looks at the thing from the perspective of the this aspect. Therefore one can say that the that and the this come from each other.... Thus, the sage is not limited to looking merely at the this or that aspect [from the finite point of view] but captures [all the aspects of] the thing in the light of nature. The this is also the that, and the that is also the this...When the this aspect and the that aspect cease to be viewed as opposite, it is called "the pivot of taking a dao point of view" dao shu 道樞; one's capturing the pivot is like one's standing at the center around which all things revolve in endless change: one can deal with endless change from the dao point of view... Therefore it is said that the best way to look at things is in the light [of nature]. ${ }^{12}$

There are two basic strategic points here. First, each thing has its various aspects, and one can take a finite perspective (as a working perspective) to look at one aspect to which the finite perspective points: one can look at its this aspect, from a this-aspectconcerned perspective, and sees it as a this, and one can also look at its that aspect, from a that-aspect-concerned perspective, and sees it as a that. Although from each limited perspective, other perspectives may appear incompatible, the basic metaphysical foundation is this: various aspects, the this aspect and the that aspect, ontologically depend on each other; various (eligible) perspectives, the this-aspectconcerned perspective and the that-aspect-concerned perspective, thus complement

\footnotetext{
${ }^{11}$ By 'distinct perspective approaches' I mean "the perspective dimensions of distinct approaches". One approach as a whole, generally speaking, has its "perspective" dimension and the "guidingprinciple" dimension, among others.

${ }^{12}$ The translation of the passages from the Zhuang-Zi here is mine. Its Chinese original is this: “物無非 彼, 物無非是。自彼則不見, 自知則知之。故曰：彼出於是, 是亦因彼。...是以聖人不由而照之於天, 亦因是也。是亦彼也, 彼亦是也, ...彼是莫得其偶, 謂之道樞; 樞始得其環中, 以應無窮。…故曰：莫 若以明。”.
} 
each other. Second, for the purpose of looking at the connection of various aspects of a thing and/or of having a comprehensive understanding of the thing, Zhuangzi also encourages us to look at things from a higher and broader point of view which transcends various finite points of view; in this way, those different aspects cease to be viewed as opposite or incompatible but complementary. With the understanding of these two strategic methodological points of Zhuangzi's objective perspectivism, one can effectively understand Zhuangzi's substantial approaches to various issues (in metaphysics, epistemology, philosophy of language, etc.) under his examination. Zhuangzi's basic methodological strategy can best be labeled (in his own term) a strategy of dao-shu-qi-wu 道樞齊物 (dao pivot that equalizes things) and can best be understood as constituting the guiding-principle core of his "transcendental" naturalism.

With this key passage of Zhuang $\mathrm{Zi}$ as one significant reference point, I stress two connections in which Searle and Zhuang Zi can be constructively bridged through the double-about character of consciousness. First, so to speak, the double-aboutness character of consciousness constitutes one "interface" engagement point between Searle's and Zhuang Zi's relevant resources. On the one hand, the "object-wholeaboutness" dimension of the double-aboutness character of consciousness is the intersubjective "base end" of the "perspective-transcending" dimension of consciousness to the extent that I have explained in the preceding section; Searle does address the "object-whole-aboutness" of consciousness, indirectly or directly via his conceptual and explanatory resources concerning what he labels "Background ability" (indirectly) and "capacity for imagination" (more directly), although in my view the concept of the capacity for imagination has its limitation to the extent as discussed in the previous section; on the other hand, as explained before, this base-end part of the "perspective-transcending" dimension of consciousness constitutes the starting-point base, on which the wisdom-cultivation-oriented portion of the "perspectivetranscending" dimension of consciousness, as addressed and emphasized by Zhuang $\mathrm{Zi}$ in terms of "the pivot of taking a dao point of view", can be further developed: those contributing elements in the wisdom-cultivation-oriented portion of the "perspective-transcending" dimension of consciousness presuppose (or are based on) the minimal holistic understanding of the whole identity of an object of study, which can be characterized in terms of the "object-whole aboutness" dimension of the double-aboutness character of consciousness.

Second, the double-aboutness character of consciousness is one substantial bridging point at which Searle and Zhuang Zi could effectively talk with, and learn from, each other. For one thing, Searle and Zhuang $\mathrm{Zi}$ can be bridged through their jointly concerned "object-aspect-aboutness" dimension of the "double-aboutness" character of consciousness. One can understand and explicate the issue of how a methodological perspective is possible in terms of a joint account of Searle's resources concerning aspectuality of intentionality and Zhuang Zi's resources concerning the legitimacy and eligibility of "this"-aspect-concerned vs. "that"-aspectconcerned perspectives (i.e., the first point of Zhuang Zi's methodological strategy); although both figures' resources concerning this issue are complementary, the 
strength of Searle's account in this connection lies in its systematic character, its articulate way of delivering points, its comprehensive characterization of various features of consciousness, and its sensitivity to scientific evidence and updated data concerning human consciousness. For another thing, if I do not misunderstand Searle, his account has yet to explicitly address the issue of the "perspective-transcending" dimension of consciousness: in Searle's own words in his "Reply": "I have not discussed adequately either here or in my published work the role of imagination" (Searle 2008, 409); in this connection, though less systematic and articulate, the strength of Zhuang Zi's methodological vision counts in: Zhuang Zi's view of legitimacy of taking (eligible) finite perspectives is intrinsically related to his "perspective-transcending" vision, as highlighted in the second part of the cited key passage in his texts.

In this way, in my view, an adequate understanding and exploration of how the cross-perspective engagement is possible needs both philosophers' resources. That is the point of bridging Searle and Zhuang Zi concerning the "double-aboutness" character of consciousness, at which we can effectively explore the issue of how the cross-perspective engagement is possible and, more generally, of how comparative philosophy is possible.

\section{ACKNOWLEDGEMENTS}

I would like to thank Hongyin Zhou and Xiaojun Ding for their helpful critical feedback to an earlier account of the double-reference character of the basic language employment (as addressed in Section 2 of this article) in my class on philosophy of language given at SJSU in Spring 2015, Hau Nguyen and Patrick Wills for their helpful critical discussion of an earlier account of the double-aboutness character of consciousness concerning objects of thought (as explained in Section 2 of this article) in my seminar class on metaphysics given at SJSU in Fall 2016, and Dean Paul Dominguez for his help on an earlier draft of this article.

\section{REFERENCES}

Crane, Tim (2013), The Objects of Thought (Oxford: Oxford University Press). Kripke, Saul (1980), Naming and Necessity (Oxford: Blackwell).

Mou, Bo (2008), "Searle, Zhuang Zi, and Transcendental Perspectivism", in Searle's Philosophy and Chinese Philosophy: Constructive Engagement, ed. Bo Mou (Leiden: Brill), 405-30.

Searle (1992), The Rediscovery of the Mind (The MIT Press).

- (1995), The Construction of Social Reality (The Free Press)

- (2008), "Reply to Bo Mou", in Searle's Philosophy and Chinese Philosophy: Constructive Engagement, ed. Bo Mou (Leiden: Brill), 431-5.

Zhuang-Zi (《莊子》), the Chinese original text. 